\section{References}

1 Minty BD, Nunn JF. Regional quality control survey of blood gas analysis. Ann Clin Biochem 1977;14:245-53.

2 Siggaard-Andersen O. Sampling and storing of blood for determination of acid base status. Scand f Clin Lab Invest 1961;13:196-204.

3 Ishikawa S, Fornier A, Borst C, Segal MS. The effect of air bubbles and time delay on blood gas analysis. Ann Allergy 1974;33:72-7.

+ Bradley JG. Errors in the measurement of blood $\mathrm{PCO}_{2}$ due to dilution of the sample with heparin solution. Br $\mathcal{F}$ Anaesth 1972;44:231-2.

${ }^{5}$ Kelman GR, Nunn JF. Nomograms for correction of blood $\mathrm{Po}_{2}, \mathrm{PCO}_{2}$
pH and base excess for time and temperature. $\mathcal{F}$ Appl Physiol 1966;21 : 1484-90.

6 Siggaard-Andersen $O$. Titratable acid or base of body fluids. Ann NY Acad Sci 1966;133:41-58.

7 Adams AP, Morgan-Hughes JO, Sykes MK. pH and blood-gas analysis. Anaesthesia $1967 ; 22: 575-97$.

8 Madiedo G, Sciacca R, Hause L. Air bubbles and temperature effect on blood gas analysis. $\mathcal{F}$ Clin Pathol 1980;33:864-7.

(Accepted 23 December 1981)

\title{
Intravenous naloxone in acute respiratory failure
}

\author{
JON AYRES， JOHN REES，TAK LEE，G M COCHRANE
}

\begin{abstract}
A 58-year-old man presented with acute on chronic respiratory failure. In the acute stage of his illness an infusion of the opiate antagonist naloxone caused an improvement in oxygen saturation as measured by ear oximetry from $74 \%$ to $85 \%$, while a saline infusion resulted in a return of oxygen saturation to the original value. When he had recovered from the acute episode the same dose of naloxone had no effect on oxygen saturation.
\end{abstract}

These findings suggest that in acute respiratory failure there may be overproduction of, or increased sensitivity to, endorphins.

\section{Introduction}

Naloxone restores the ventilatory response to added inspiratory loads in some patients with chronic stable airflow obstruction. ${ }^{1}$ We report on a patient with acute on chronic respiratory failure in whom naloxone improved both oxygen saturation and tidal ventilation, suggesting that endorphins play a part in acute respiratory failure.

\section{Case history}

In 1968 a 46-year-old man presented with recurrent supraventricular tachycardias and was found to have a paralysed right hemidiaphragm, which recovered spontaneously over the subsequent three months. In 1975 he complained of daytime somnolence, which worsened over the next five years, by which time breathlessness limited his exercise tolerance to 50 yards and he was thus admitted to hospital with a respiratory tract infection. He was wheezy and in right heart failure, and had paradoxical movement of the abdominal wall on inspiration. Proximal muscles were weak in his arms and legs. Chest radiography showed that the left hemidiaphragm was paralysed. Results of tests of respiratory function were: forced expiratory volume in one second $0.55 \mathrm{l}$ (predicted $2.6-3.5 \mathrm{l}$ ), forced vital capacity $1.601(4.0-5.0 \mathrm{l}$ ), total lung capacity $6 \cdot 61(5 \cdot 9-7 \cdot 21)$, and residual volume $4 \cdot 51(1 \cdot 9-2 \cdot 71)$. He required mechanical ventilation for one week, after which he was able to breathe spontaneously. Tests of his respiratory and skeletal

Department of Thoracic Medicine, Guy's Hospital, London SE1 9RT JON AYRES, MB, MRCP, research registrar

JOHN REES, MA, MRCP, senior registrar

TAK LEE, MB, MRCP, registrar (present appointment: clinical lecturer, Cardiothoracic Institute, Brompton Hospital, London SW3)

G M COCHRANE, MB, MRCP, consultant muscles after ventilation showed: vital capacity (supine) 1.551 ; vital capacity (erect) 2.151 ; maximal inspiratory pressure $1.9 \mathrm{kPa}(19 \mathrm{~cm}$ $\mathrm{H}_{2} \mathrm{O}$ ) (predicted $>6.9 \mathrm{kPa}\left(70 \mathrm{~cm} \mathrm{H}_{2} \mathrm{O}\right.$ )); maximal expiratory pressure $7.8 \mathrm{kPa}\left(80 \mathrm{~cm} \mathrm{H} \mathrm{H}_{2} \mathrm{O}\right)$ (predicted $>13.7 \mathrm{kPa}\left(140 \mathrm{~cm} \mathrm{H}_{2} \mathrm{O}\right)$ ); and transdiaphragmatic pressure $0.3 \mathrm{kPa}\left(3 \mathrm{~cm} \mathrm{H}_{2} \mathrm{O}\right.$ ) (predicted $>2.5 \mathrm{kPa}$ $\left(25 \mathrm{~cm} \mathrm{H}_{2} \mathrm{O}\right)$ ). Electromyography showed evidence of a myopathy of the intercostal muscles. Creatinine phosphokinase concentration was normal. A polygraphic sleep study showed no nocturnal apnoea but periods of hypopnoea associated with falls in oxygen saturation from $75 \%$ to $34 \%$. Crossed auditory evoked potentials were normal. A rocking bed improved his episodes of night-time desaturation.

While he was being weaned off the ventilator a bolus of $0.4 \mathrm{mg}$ naloxone intravenously caused an increase in respiratory rate and oxygen saturation (as measured by an ear oximeter). The $\mathrm{pH}$ rose from $7 \cdot 42$ to $7 \cdot 43$; oxygen pressure rose from 4.1 to $4.3 \mathrm{kPa}$ (31 to 32 $\mathrm{mm} \mathrm{Hg}$ ); carbon dioxide pressure fell from 8.65 to $8.17 \mathrm{kPa}$ (65 to 61 $\mathrm{mm} \mathrm{Hg})$; bicarbonate concentration fell from 36 to $35 \mathrm{mmol}(\mathrm{mEq}) / 1$; and base excess fell from +15 to $+14 \mathrm{mmol}(\mathrm{mEq}) / 1$. A second bolus of $2 \mathrm{mg}$ caused an increase in tidal volume and made him agitated and hot. No opiate drugs had been administered during his admission. Infusions of naloxone $(0.2 \mathrm{mg} / \mathrm{min})$ and of physiological saline were compared in a double-blind manner (figure). Five minutes after the

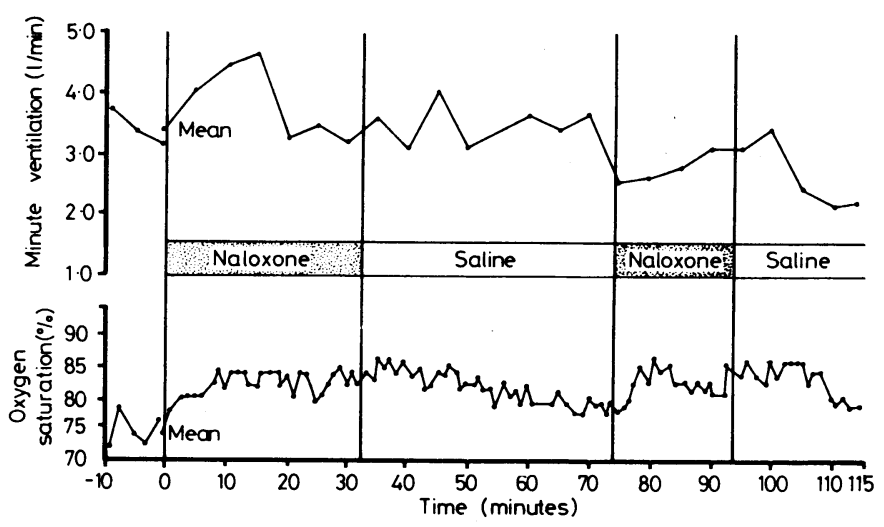

Changes in minute ventilation and oxygen saturation with infusions of naloxone $(0.2 \mathrm{mg} / \mathrm{min})$ and saline.

beginning of the naloxone infusion minute ventilation rose from a baseline value of $3.121 / \mathrm{min}$ to $4.641 / \mathrm{min}$ through an increase in tidal volume, oxygen saturation rising from $74 \%$ to $85 \%$ over 15 minutes. During saline infusion minute ventilation remained constant and oxygen saturation fell to $75 \%$. When naloxone was restarted oxygen saturation rose to $85 \%$ while tidal volume and respiratory rate were unchanged. Minute ventilation fell towards the baseline value on reinfusion of saline.

Regular treatment was started with subcutaneous naloxone ( $2 \mathrm{mg}$ four times daily). A repeat study three weeks later, when he was well, 
showed no response to naloxone. Three months later he was admitted in respiratory failure refractory to all treatment. Necropsy showed chronic bronchitis, bullous emphysema, and right ventricular hypertrophy. The intercostal muscles were thin and fibrous, and histology of these and the diaphragm and psoas showed changes of chronic denervation. Histology of the spinal cord was not obtained.

\section{Discussion}

Naloxone reverses the apnoeic response to hypoxia in neonatal rabbits ${ }^{2}$ but, even in large doses, has no effect on respiration in hypoxic man. ${ }^{3}$ Respiratory failure in this patient was thought to be caused by a combination of chronic airflow obstruction and weakness of the respiratory muscles (possibly due to chronic spinal muscular atrophy). ${ }^{4}$ Intravenous naloxone produced an increase in minute ventilation and general agitation when he was acutely ill. The increase in oxygen saturation was greater than expected for the increase in ventilation, suggesting improved ventilation-perfusion matching, but the response occurred only in the acute illness.

These findings suggest that there may be overproduction of, or increased sensitivity to, endorphins in acute respiratory failure. Naloxone is beneficial in shock, ${ }^{5}$ the postulated mechanism being that endorphins inhibit the interaction of catecholamines with their receptors. Such an action might account for the changes in ventilation-perfusion balance in our patient.

Requests for reprints should be sent to Dr J Ayres, Department of Thoracic Medicine, Guy's Hospital, London SE1 9RT.

\section{References}

1 Santiago TV, Remolina C, Scoles V, Edelman NH. Endorphins and the control of breathing. $N$ Engl F Med $1981 ; 304: 1190-5$.

2 Grunstein MM, Hazinski TA, Schlueter MA. Respiratory control during hypoxia in newborn rabbits: implied action of endorphins. $\mathcal{F} A p p$ Physiol 1981;51:122-30.

${ }^{3}$ Fleetham JA, Clarke H, Dhingra S, Chernick V, Anthonisen NR. Endogenous opiates and chemical control of breathing in humans. Am Rev Respir Dis 1980;121:1045-9.

${ }^{4}$ Haas H, Johnson LR, Gill TH, Armentrout TS. Diaphragm paralysis and ventilatory failure in chronic proximal spinal muscular atrophy. $A m$ Rev Respir Dis $1981 ; 123: 465-76$.

5 Anonymous. Naloxone for septic shock. Lancet 1981 ;i:538-9.

(Accepted 8 fanuary 1982)

\title{
Medial arterial calcification and diabetic neuropathy
}

\author{
M E EDMONDS, N MORRISON, J W LAWS, P J WATKINS
}

\begin{abstract}
$X$-ray examinations of the feet, knees, and hands were performed on 20 diabetics with severe neuropathy and 20 diabetics with no evidence of neuropathy but with a similar mean age and duration of diabetes. All were under 53 years old with no clinical evidence of peripheral vascular disease. Medial arterial calcification was much more common and extensive in the patients with neuropathy, occurring in the feet in 15 and in the hands in eight compared with in four $(p<0.001)$ and none $(p<0.001)$ of the controls respectively. Although there was some correlation between calcification and both proteinuria $(p<0.05)$ and proliferative retinopathy $(p<0.02)$, the association between calcification and neuropathy (p <0.001) was much stronger.
\end{abstract}

Neuropathy, with sympathetic denervation of the smooth muscle of the tunica media, may be important in the aetiology of medial arterial calcification.

\section{Introduction}

Medial arterial calcification, otherwise known as Monckeberg's sclerosis, ${ }^{1}$ was described in diabetics in $1924,{ }^{2}$ but its aetiology and importance remain unknown. It is easily detected on $x$-ray films by its classical "pipe-stem" or "tramline" appearance (see fig 1). Previous observations have indicated that the calcification

\footnotetext{
Diabetic Department and Radiology Department, King's College Hospital, London SE5 9RS

M E EDMONDS, MB, MRCP, research fellow and honorary lecturer N MORRISON, MB, FRCR, senior registrar in radiology

J W LAWS, FRCP, FRCR, consultant radiologist

P J WATKINS, MD, FRCP, consultant physician
}

is predominantly related to the age of the patient and the duration of diabetes. ${ }^{3-5}$ During a recent study of blood flow in the foot in patients with neuropathy, however, it was noted that medial wall calcification was particularly common in diabetics with severe neuropathy. ${ }^{6}$ There were two aims of the present study: firstly, to determine whether medial wall calcification was a specific complication of diabetes, not just related to age and duration of disease, and, secondly, to consider its relation to neuropathy, which could be important in its pathogenesis.

\section{Patients and methods}

The presence of calcification was determined in two groups of patients, the first consisting of 20 diabetics with neuropathy and the

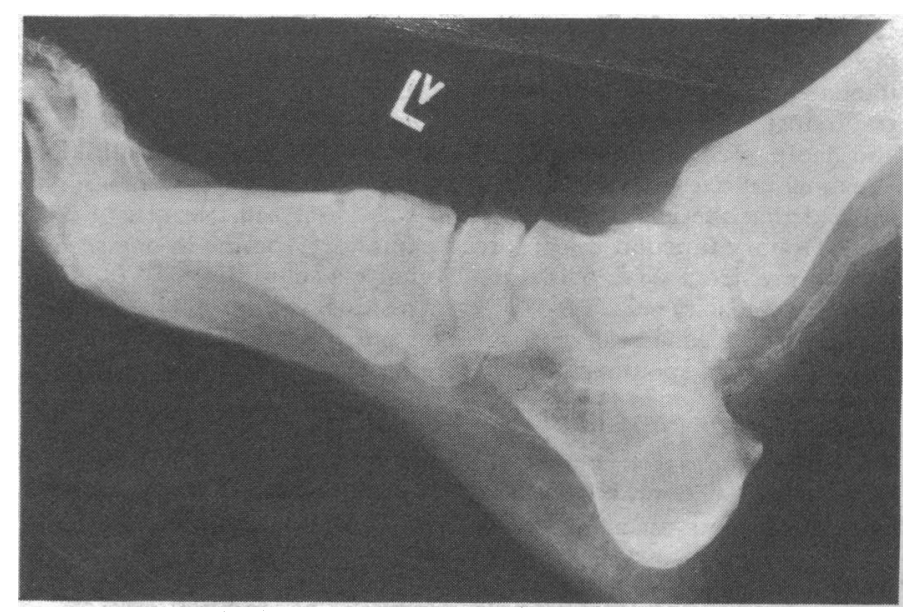

FIG 1-Lateral view of foot showing characteristic "tramline" appearance of medial arterial calcification. 